\title{
The origin and detection of spike-like anomalies in soil gas radon time series
}

\author{
L. Lynn Chyi,${ }^{1 *}$ Thomas J. Quick, ${ }^{1}$ Tsanyao Frank YAnG ${ }^{2}$ and Cheng-Hong Chen $^{2}$ \\ ${ }^{1}$ Department of Geology and Environmental Science, University of Akron, Akron, OH 44325-4101, U.S.A. \\ ${ }^{2}$ Department of Geosciences, National Taiwan University, Taipei 106, Taiwan
}

(Received April 25, 2008; Accepted February 9, 2009)

\begin{abstract}
Desorption of radon is of short duration but longer than telluric noises and is usually accomplished in less than one minute based on our binary event counting with a 16 second interval. Adapting an hourly counting time schedule, telluric noises as well as transient variation of radon anomalies of a few hours duration can be excluded but not the spike-like anomalies of a few minutes duration. The time series of soil gas radon, as recorded continuously in a redesigned ditch located inside an active fault zone, has sporadic spike-like anomalies. The anomalies could represent desorbed radon from shallow sources as observed from a similar detecting system located near a construction site. Radon release due to compressive stress is related to compressive back-filling activities. Spike-like anomalies, on the other hand, are related to caisson auguring shear activities. Charge transfer related to electrokinetic potential phenomena may have resulted in the sudden radon releases and caused spike-like anomalies. The timing of the anomalies provides good information on the timing of electokinetic potential change as a result of outward propagation of stress from hypocenter. With multiple monitoring stations, the location, timing, and magnitude of the incoming earthquake can then be calculated or graphically derived.
\end{abstract}

Keywords: radon detection, spike-like anomaly, time series, soil gas, earthquake cycle

\section{ORIGIN OF RADON}

Nazaroff (1992) summarized that radon generated from radioactive decay of uranium and thorium in the upper several meters of the crust can migrate during their brief lifetime into the atmosphere. Radon has three natural occurring nuclides ${ }^{222} \mathrm{Rn},{ }^{219} \mathrm{Rn}$, and ${ }^{220} \mathrm{Rn}$ that are derived from the decay of ${ }^{238} \mathrm{U},{ }^{235} \mathrm{U}$, and ${ }^{232} \mathrm{Th}$, respectively. The respective half-lives are 3.8235 days, 3.96 seconds, and 55.6 seconds. Radon is chemically inert, the heaviest natural occurring gas, and capable of forming clathrates with water molecules. Being longer in half-life, ${ }^{222} \mathrm{Rn}$ generated from rocks and minerals may enter pore fluids and migrate a significant distance from the site of generation along certain conduits such as active faults. Due to its energetic decay from $\mathrm{Ra}$, the ${ }^{222} \mathrm{Rn}$ daughter is likely to be charged and thus sensitive to telluric charge variations.

Nazaroff (1992) stated that radon atoms in soil are distributed among the four states: 1) bound within the solid soil grains, 2) sorbed onto the surface of soil grains, 3) dissolved within water contained in the soil pores, and 4) dispersed within the gas in soil pores. In other words, radon atoms or cations generated from recoil are distrib-

\footnotetext{
*Corresponding author (e-mail: lchyi@uakron.edu)
}

Copyright (c) 2011 by The Geochemical Society of Japan. uted among a solid, a sorbed, an aqueous, and a gas phase. Above groundwater table, radon atoms and ions are partitioned between solid, sorbed, and gas phases. Below groundwater table, they are distributed among all four phases. Near the surface, radon can be desorbed depending on the atmospheric condition and changes of stress forces in a fault zone. Even though radon can be dissolved in water as radon clathrate, it is most likely adsorbed as a free atom on the ice surface as demonstrated thermodynamically by Eichler et al. (2000). This implies that radon can remain dissolved in groundwater as clathrates, yet it is adsorbed on the surface of soil and mineral particles under groundwater table as free atoms.

The sorbed free radon atoms and dispersed radon in groundwater can be released when the subterranean conditions such as $\mathrm{pH}$, temperature, and soil gas flux change due to crustal stress and geothermal perturbations (e.g., Laskar et al., 2011; Montazeri et al., 2011; TchorzTrzeciakiewicz and Solecki, 2011; Woith et al., 2011; Yang et al., 2011). Responding to stresses, groundwater can move upward and down the geothermal gradient in a fault zone. Liu et al. (2001) gave an average value of $42^{\circ} \mathrm{C} / \mathrm{km}$ for the Central Range of Taiwan. Solubility of radon doubles for roughly every $22^{\circ} \mathrm{C}$ decrease in temperature (Lide, 2006). Therefore, upwelling of deeper groundwater is unlikely to release its dissolved radon. Crampin and Zatsepin (1997) showed that fluid-filled microcracks respond almost immediately to changes in 


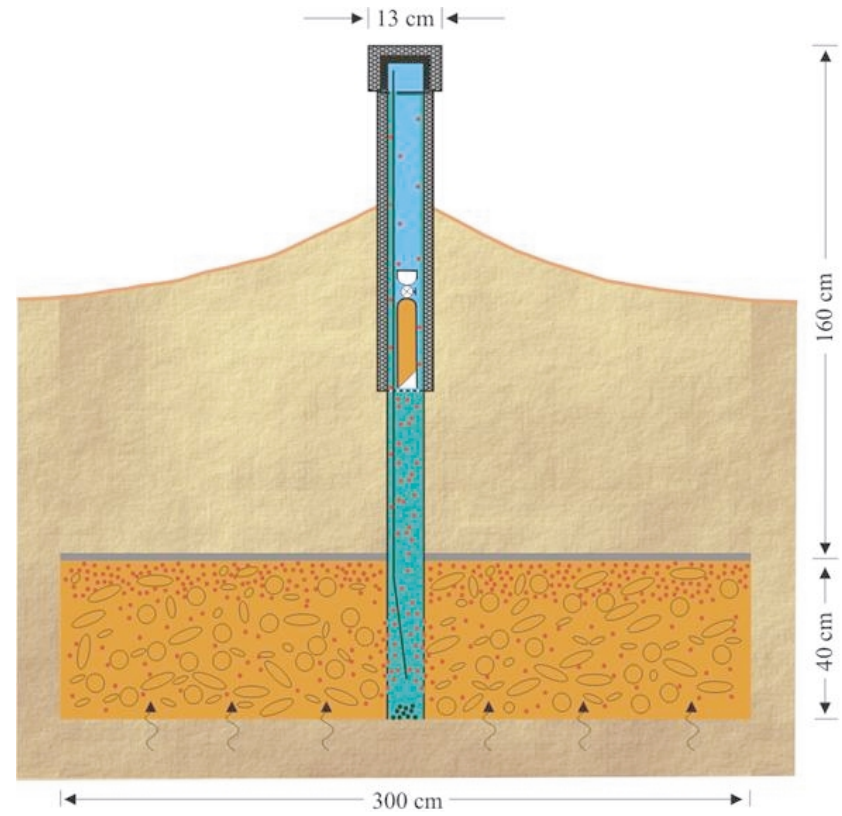

Fig. 1. Schematic diagram of the radon detector assembly and the monitoring station. The insulating material is placed between the first and second layer of $P V C$ pipe. The vertical line curved at bottom is a small tube for the introduction of insect repellant.

stress and could be the main reason for shear wave splitting. This means that the physical and chemical conditions of groundwater such as $\mathrm{pH}$ and temperature can change as crustal stress is advanced through the area. Groundwater property variation can, therefore, induce a change in radon solubility. But the drastic spike-like anomalies must be resulted from a more drastic release of absorbed radon as shear stress acts on fault blocks.

\section{DETECTION OF RADON}

A silicon photodiode solid state detector has been used for the continuous recording of soil gas radon since late 2000 in our monitoring stations in Taiwan. The electronics of the radon detection including the grounding of the circuit, the high voltage conversion, and count registration process, is described in the US patent application (Chyi, 2006). The radon counts were registered in a binary event logger every 16 second (Chyi et al., 2001) in the earlier version of the detector system. Starting in January, 2002, a redesigned second generation counting system took counts once every hour with the system housed in a 3 " perforated PVC pipe and then placed in a 4" PVC pipe housing standing upright in a constructed ditch (Fig. 1) lined with clean gravel and covered with a liner at approximately $1 \mathrm{~m}$ below the ground surface. The 3 " diameter PVC housing has a polyethylene membrane at the

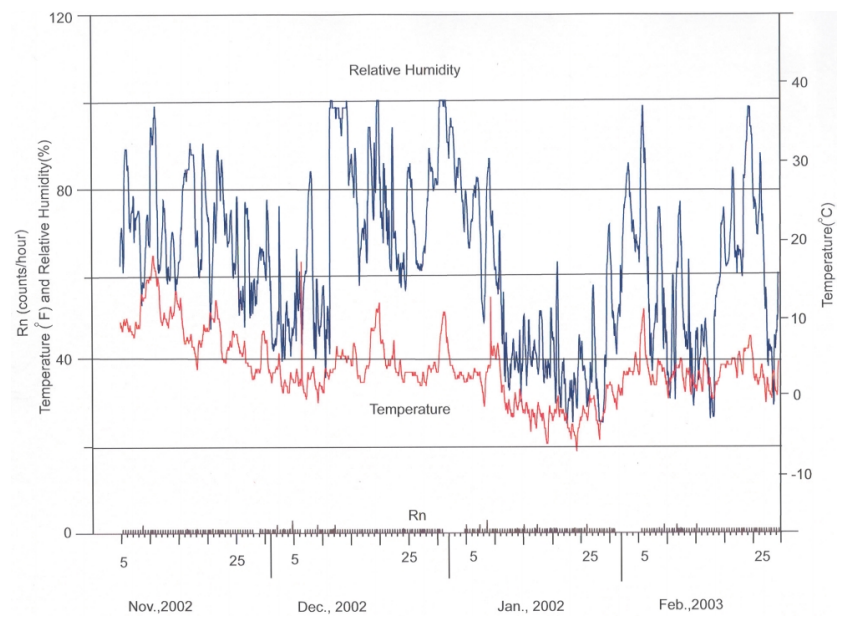

Fig. 2. Radon time series of Akron 1 recorded between November 5, 2002 and February 28, 2003 with concurrent recording of relative humidity and temperature of ambient atmosphere (after Chyi et al., 2005).

lower end. The membrane can discriminate against the short-lived radon nuclides. When it is placed at a $45^{\circ}$ angle with respect to the detector system axis, moisture will condense on it and drips away as it condense, and thus serves as a moisture discriminator (Chyi, 2006). Clean gravel has a permeability of $10^{-8} \mathrm{~m}^{2}$. It is more permeable than any other natural material; hence convective flow is the dominant mechanism for the migration of radon into the ditch. The soil gas receiving zone of the ditch will reach equilibrium approximately 10 days or 3 halflives of ${ }^{222} \mathrm{Rn}$ after the closing and sealing of the external $4 "$ PVC pipe that housed the detector assembly. It is illustrated in Fig. 8 at the beginning of the time series and also after each inundation events of the Taiwan 3 time series.

As shown in Fig. 2, the ditch and receiving zone design is insensitive to atmospheric temperature, pressure, and moisture variations (Chyi et al., 2005). Time series recorded from November, 2002 to February, 2003 at the University of Akron or Akron 1 shows that radon levels remained low and essentially unchanged as expected for a site over the North American craton. During this counting period, the ambient temperature varied between $18^{\circ} \mathrm{C}$ down to $-7^{\circ} \mathrm{C}$ and the relative humidity varied between $100 \%$ down to $25 \%$. The soil temperature was about $10^{\circ} \mathrm{C}$, so at the coldest temperature, there actually was a downward airflow (Fig. 2) but it did not affect the radon count.

Typical radon time series registered by the radon counting system is shown as count/hour (Fig. 3). The series has spike-like anomalies, such as that one recorded on January 25, 2002, and gentle radon variation of a few day duration, such as the 30 counts/hour increase from 80 to 110 recorded from January 25 through 28 . As men- 


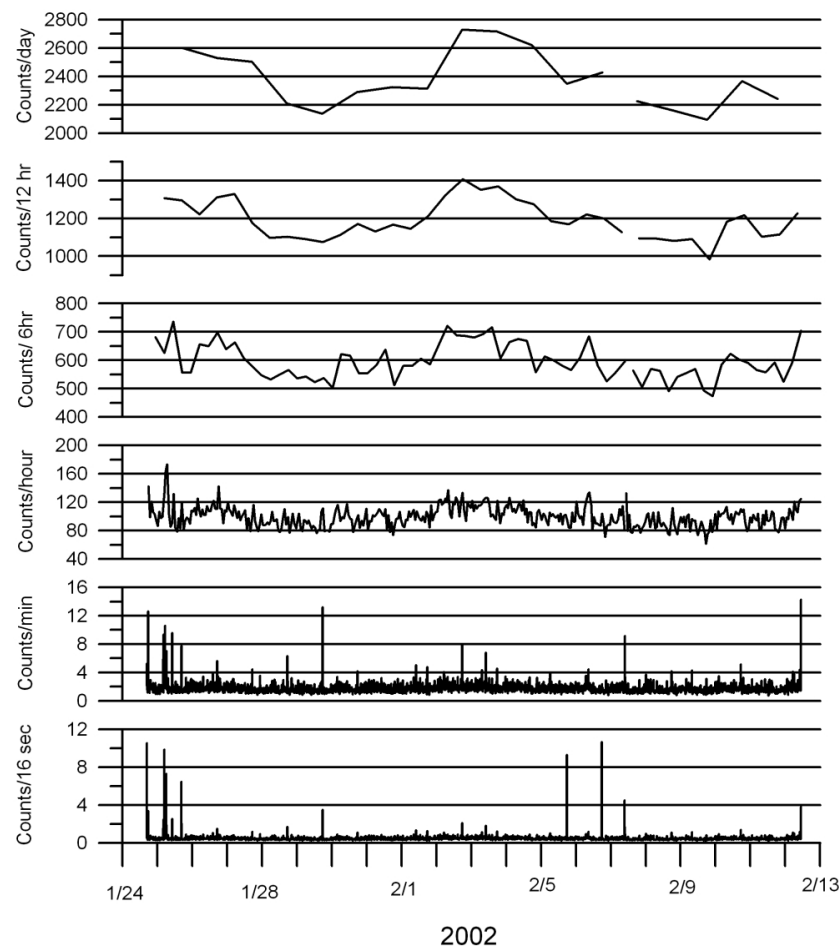

Fig. 3. Binary event 16 second counting result at Taiwan 1 recorded between late January and mid-February, 2002. The event counting is recalculated to counts/minute, counts/hour, counts/6 hour, counts/12 hour, and counts/day to show how the telluric noises are filtered and spike-like anomalies are preserved.

tioned by Hoppel et al. (1986), radon emission may be related to telluric electric noises. This type of radon releases are visible during the binary event 16 second counts in 2002 as sharp peaks in counts/16 and counts/min (Fig. 3) but are eliminated at counts/hour. Spike-like anomalies visible at hourly counting intervals become invisible if the counting interval becomes longer than 12 hours. It can be demonstrated that the spike-like anomaly become essentially undetectable if the counting interval is longer than a day. Register radon counts on hourly basis appears to be appropriate for the purpose of detecting the spikelike anomaly and eliminating unwanted noises. In the mean time, it can be argued that only a continuous counting of radon in real time with a counting interval of a few hours or less is capable of recording these spike-like anomalies (Chyi, 2006). Small duration of observed spikes of a few hour duration may have been sporadic release of radon through active fault from somewhat deeper sources, several hundred meter range, due to change of groundwater properties. Yang et al. (2005) reported such kind of transient temperature variations at Taiwan 1 site.

Using a daily time constant as calculated by running average of the 16 second event counts, deviation due to

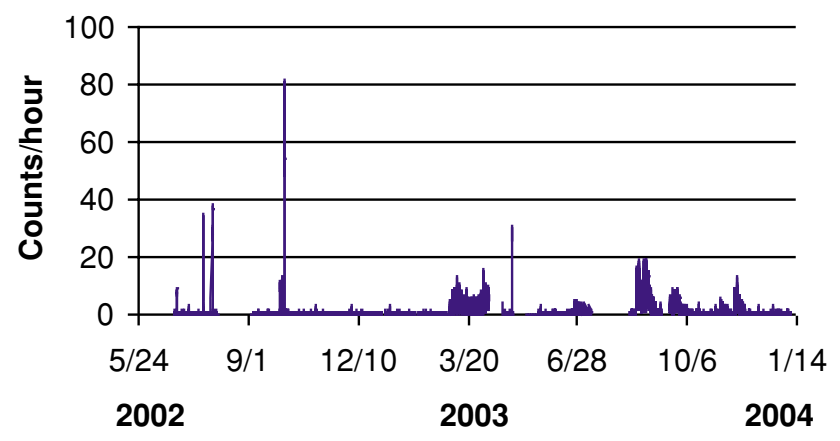

Fig. 4. University of Akron campus map showing the location of Akron 1, North Campus parking and Student Union buildings. Bright yellow color indicates glacial deposits, gray color a shale unit, and buff color the conglomeritic sandstone unit. Arrows within the sandstone unit indicate the direction of groundwater flow.

counting statistics, square root of the registered counts, can be calculated. This running average is used as counting background so the radon variations a few day durations will not affect the determination of spike-like anomalies. The plus and minus standard deviation lines can then be drawn and superimposed on the hourly count time series for the identification of spike-like anomalies. Statistically speaking, the chance of misidentify the anomalies above one standard deviation line is $33 \%$, and the anomalies above two standard deviation line is $5 \%$. Earthquakes, that could cause major damages, are shown (Chyi et al., 2005, 2007) to generate anomalous radon release at least one standard deviation above the counting background.

\section{MONITORING Site}

Akron is situated in northeastern Ohio and is will within the North American craton, with only small magnitude earthquakes occurring once in a long time. In other words, we do not expect to see elevated radon levels or spike-like anomaly in the radon time series (Fig. 2). The average background counts are around 1 count/hour and there was no spike-like anomaly observed for the period, November, 2002 through February, 2003. However, during the construction of the student union and north campus parking building from 2002 through early 2004, elevated radon level was observed. The north campus parking building is located 92 to $155 \mathrm{~m}$ north of the Akron 1 monitoring station, and the student union building is 58 to $155 \mathrm{~m}$ south of this station (Fig. 4). The area is underlain by a $40 \mathrm{~m}$ thick conglomeratic sandstone aquifer located just a few meters below a gentle westward sloping surface. The sandstone unit strikes almost due north-south. It dips slightly to the east. Many buildings on campus 


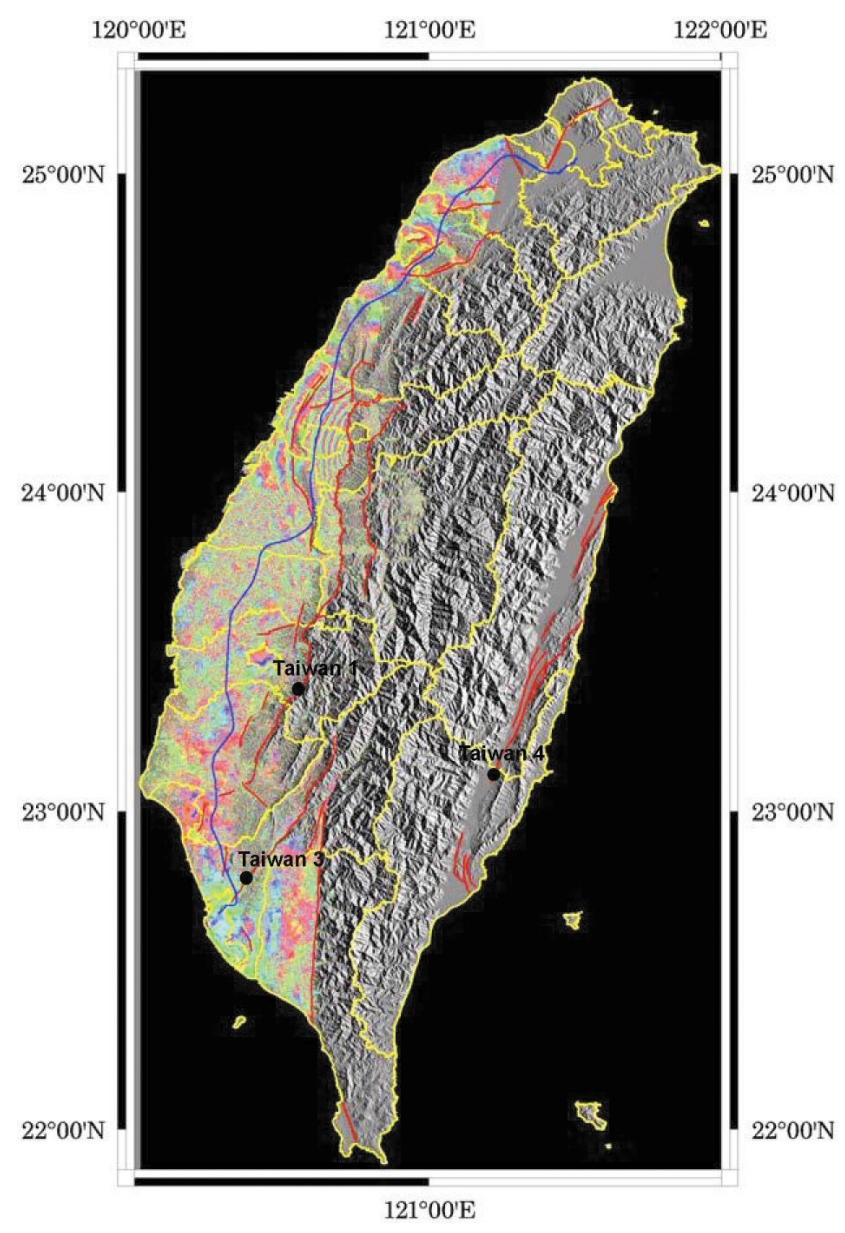

Fig. 5. InSar map of Taiwan (Wang et al., 2005) with the locations of Taiwan 1, 3, and 4 indicated.

were built with caissons directly anchored on this sandstone unit. This porous conglomeratic sandstone serves not only as a conduit for groundwater migration but also as a conduit for soil gas migration.

The first monitoring station in Taiwan, Taiwan 1, was established in October of 2000. It is located on a gravelly sandy river terrace within a fault zone created by six active faults. The superfacial soil layer above groundwater table is at least $2 \mathrm{~m}$. This fault zone is very wide and has a large lateral extension of approximately $600 \mathrm{~m}$. As a result, the deep source radon counts are high (Chyi et al., 2001). The average background radon counts/hour at this site is about 80 . The second station, Taiwan 3 , was established in a mud volcano area found within Chishan Fault zone with a smaller lateral extension of about $60 \mathrm{~m}$. The station started to function in March of 2004 (Chyi et al., 2005). The radon of deeper origin is not as high as Taiwan 1 because of the low permeability nature of the soil. The superfacial soil layer above groundwater table is about $2 \mathrm{~m}$. This drainage situation at this site is being

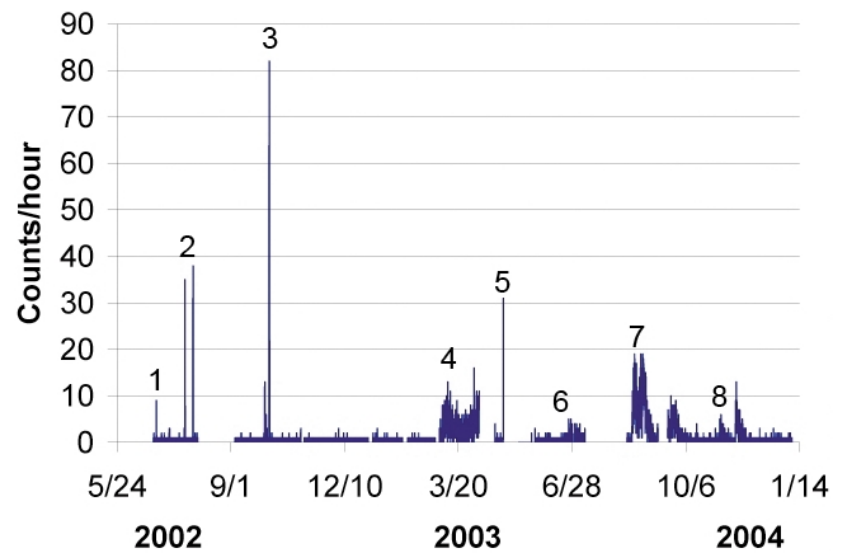

Fig. 6. Radon time series recorded at Akron 1 between early June, 2002 and early January, 2004. Spike-like radon emission related to caisson auguring and radon elevation with a natural decay related to back-filling activities are clearly visible. Events 1 through 3 were caisson auguring activities at north parking building, event 4 was back-filling activities at student union building, event 5 was caisson auguring at student union building, and events 6 through 8 were back-filling activities at student union buildings.

improved at this time to resolve the intermittent flooding problems during typhoon season. Both Taiwan 1 and 3 are located in southwestern Taiwan. Taiwan 4 is located in east central Taiwan and within the Chishang Fault zone with a width of less than $100 \mathrm{~m}$ lateral extension ( $\mathrm{Fu}$ et al., 2009). It was established in April of 2007. The average background radon counts/hour is around 30 (Fig. 5). All these three monitoring sites are sensitive to tectonic changes as indicated by the lacking of InSar fringes over the area (Fig. 5). That means that the stress comes from the Philippine Sea plate in the southwest is not absorbed by surfacial soil layer as seen in most part of the western lowland of Taiwan.

\section{INTERPRETATION OF TIME SERIES}

The spike-like anomalies can be related to caisson auguring shear activities either at north campus parking or the student union building, and elevated radon levels without spike-like anomalies can be related to backfilling activities at the student union building (Fig. 6). There were no back-filling activities around the north parking building. Caisson auguring activity at the student union building was only done once on April 28, 2003. Caisson auguring activities represent several drillings separated by short time interval.

Backfilling activities can last a few days. Other construction activities are over $300 \mathrm{~m}$ from the monitoring station and did not release detectable radon. Caisson auguring applied shear stress to the sandstone unit, and 
a)

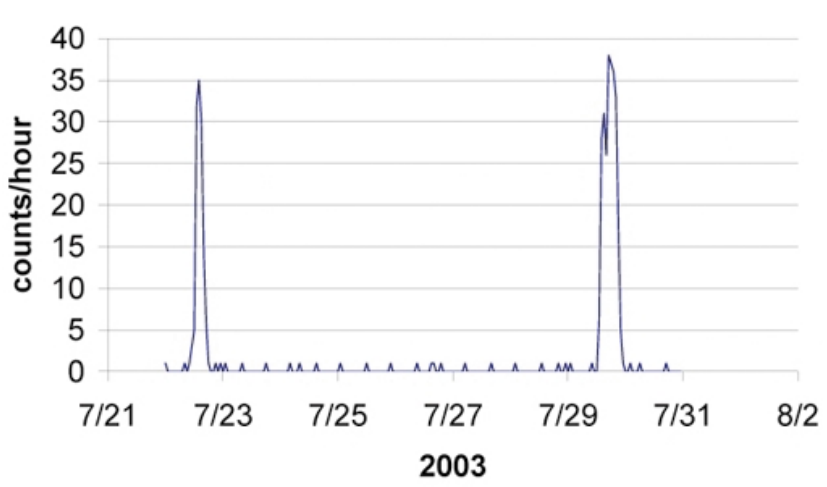

b) Back-Filling

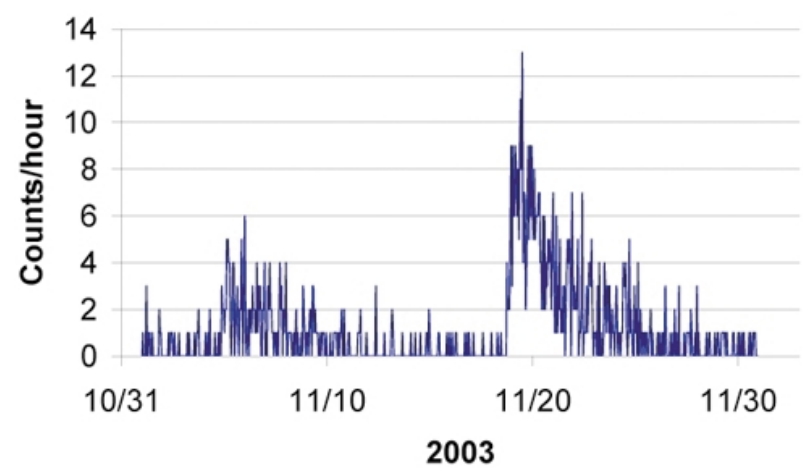

Fig. 7. a) Quick rise and fall of radon level within the same day of caisson auguring. The shear stress of the auguring activities on July 22 and July 29 produced the sharp peak approximately 6 hours after the starting of drilling. b) Quick rise but slow decay of radon level as a result of back-filling activities at Student Union building. The decaying of radon level of early and late November, 2003 give an average apparent decay half-life of 3.6 days.

the spike-like anomalies took 1 to 6 hours to develop. Drilling usually started at 7 am and the spike started to show sometime between 8 am and $1 \mathrm{pm}$. The distance and time as indicated gives us a traveling velocity of about $0.7 \mathrm{~km} /$ day. If we use preparation zone equation, $R_{\max }=$ $10^{0.43 \mathrm{M}}$, (Dolbrovolsky et al., 1979) where the limit of preparation zone as maximum distance $R_{\max }=0.16 \mathrm{~km}$ as stated in the previous paragraph, and magnitude $M$ can be calculated to be equals to 2.7 .

The detailed variation of the radon level around event 2 is amplified in Fig. 7a to show the salient variation. The radon level stayed high at 83 counts/hour for the duration of the auguring and then dropped off to the normal daily level, a few counts a day. Back-filling activities were accomplished by a 15 ton vibro-roller that applied compressive stress to the immediate area. The compressive stress affected the underlying sandstone to a greater depth than the auger drilling. A portion of event 8 is amplified to show the increase and decrease of the radon level, as it responded to the back-filling activities (Fig. 7b). The compressive stress caused the radon level to increase up to 13 counts/hour level. However, the elevated radon level could last continuously for a few days after the back-filling was finally finished. In fact, the elevated radon level appeared to decay away at a half-life of $3.6 \mathrm{day}^{-1}$. This phenomenon could be the decrease of vibration amplitude of the vibro-roller as the back-filling sediment is gradually packed. Initial packing of backfilling sediments could generate a small spike-like anomaly.

Caisson auguring generates spike-like anomalies presumably from radon released from the upper part of the sandstone. It is released quickly and has basically no residual release after auguring activities stop. Back-filling, on the other hand, releases radon from a larger portion of the sandstone. The residual release of radon can last a few days. Since there is no tectonic activities in Akron area, the observed auguring and backfilling activities must be the sources for the detected radon anomalies. As a matter of fact, the shearing and pounding vibrations can be felt in the building next to Akron 1. Caisson auguring generates shear stress and a sudden radon burst. Backfilling generates compression stress and releases radon from a large volume of rocks. By analogy to this finding, general compression within a fault zone could produce elevated radon level but only the actual moving of fault blocks, rotational or transitional, is capable of generating spike-like anomalies. Because this sandstone is a local aquifer, both absorbed and dissolved radon could be released as a response to the compressive or shear stress as the corresponding $\mathrm{pH}$ and temperature changes.

The current finding indicates that the radon monitoring site should be away from human interferences including construction, traffic, military, mining, hydraulic power generation, and accidental activities. In studying natural earthquakes along the extension of Tanlu Fault in Russia, Mackey et al. (2003) in indicated that the detection of natural earthquakes can be contaminated by industrial explosions. In this part of Russia, the industrial explosions include mining of tin, gold, and coal, as well as in the construction of roads, railways and dams. Most of these artificial activities have magnitudes of about 2.0 and occur during local daytime. This also implies that the monitoring site should be away from areas with mass wasting potentials.

When comparing these local findings related to the compressive and shear stresses from the construction activities with the time series actually recorded at Taiwan 1 and 3 (Fig. 8), it is possible that the elevated radon levels are related to compressive stress, and spike-like anoma- 


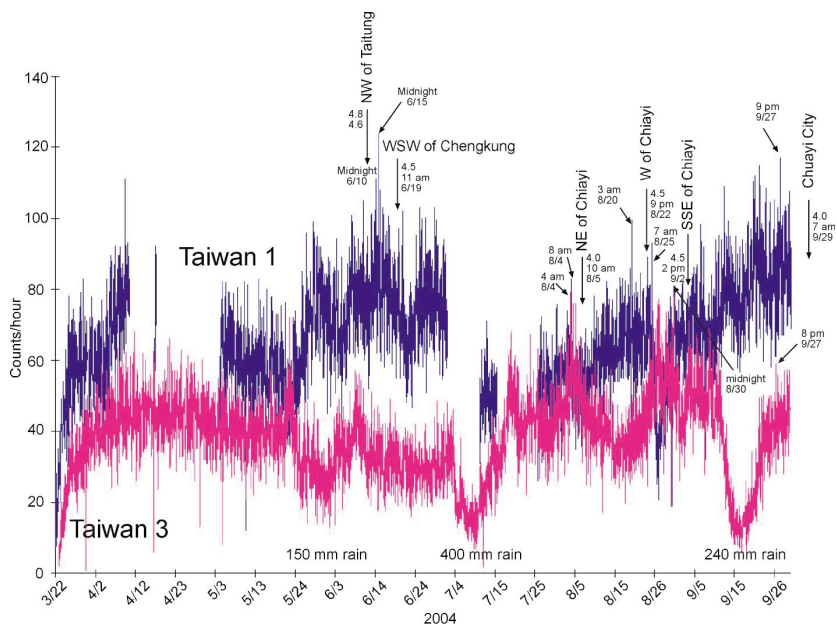

Fig. 8. Radon time series recorded at Taiwan 1 and 3 sites between March 22, and September 28, 2004. The effect of ditch flooding is indicated in the amount of rain precipitated. Arrows with time and date are precursors and the ensuing earthquakes are identified with down arrows.

lies are largely related to shear stress. It is not unusual for the time series to have many spikes because perceivable earthquakes, $>M=4.0$, occurred on average once or twice a month and smaller, $<M=4.0$, earthquakes once a day. Time scale spanning over a month or less is usually used for the actual analysis and forecast. Hoppel et al. (1986) indicated that the primary source of ions in the planetary boundary layer over land is natural radioactivity originating from the ground either as radioactivities from radioactive elements or from radioactive gases escaping from the ground. One source is the $\alpha, \beta$, and $\gamma$ particles radiating directly from the ground surface, and the second source is radioactive gases and their daughters exhaled from the ground. The amount of radon that escapes depends on the amount of ${ }^{226} \mathrm{Ra}$ and ${ }^{232} \mathrm{Th}$ in the ground, the type of ground cover, and the porosity, dampness, and the temperature of the soil. Hoppel et al. (1986), however, could not distinguish between the local and global components of these radioactive sources. It appears that the long term radon variations are local in nature and are likely to be related to the compressive stresses from the movement of plates, and the secular variation of heat flow. The spike-like anomalies, on the other hand, are likely to relate to shear stress of fault blocks and quick release of radon absorbed on the surface of the blocks. Since stress is assumed to propagate outward from a hypocenter (Crampin and Zatsepin, 1997), these spikelike anomalies as recorded at different monitoring stations are likely to reflect the timing of stress propagation through the monitoring station. With this consideration, the spike-like anomalies as recorded at various stations should provide important information regarding to the

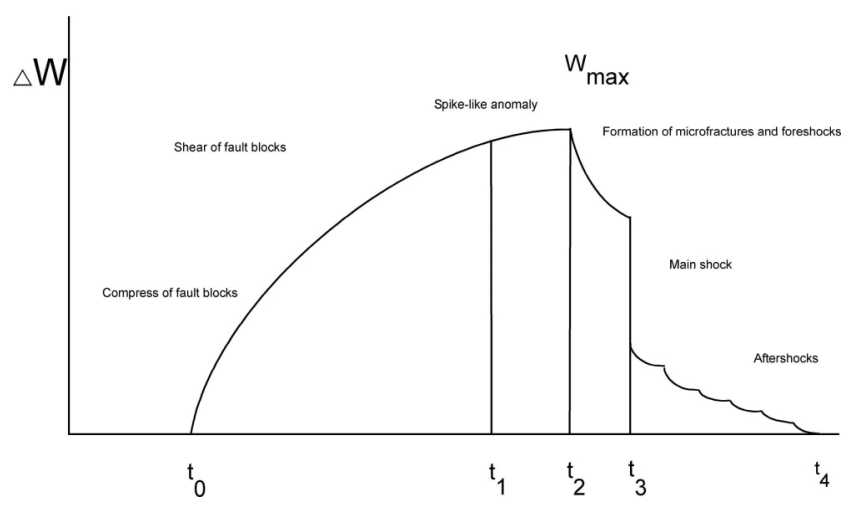

Fig. 9. Modified Dolbrovolsky's model (Dolbrovolsky et al., 1979) for an earthquake potential energy buildup, maximum, and decay with possible events indicated.

preparation of earthquake and should be interrelated regionally in time.

In their study of electromagnetic precursors of the 2004 Parkfield earthquake, Park et al. (2007) concluded that piezoelectricity and electrokinetic phenomenon are the two most commonly cited causes for transient electric potentials; both have been verified repeatedly in the laboratory studies. However, they believed that electrokinetic or self potential phenomenon associated with fluid flow prior to earthquakes is the major source instead of piezoelectricity. Electric potentials are generated to counteract charge transfer and separation by bulk flow of an ion fluid through a negatively charged silicate matrix that preferably attracts cations (Morgan et al., 1989). The charge transfer and the ensued counter charge must induce $\mathrm{pH}$ and temperature changes of the groundwater flow and that in turn alter the emanation coefficient of radon from the surface of soil and mineral particles in the fault zone. As a result, the charge transfer can affect not just the absorbed radon and dispersed radon in groundwater; but it can also affect the radon bound in the solid phase. The charge transfer is likely to be of short duration and may cause a short burst of radon that is recorded as a spike-like anomaly. The ${ }^{3} \mathrm{He} /{ }^{4} \mathrm{He}$ ratios as studied by Yang et al. (2003) suggested that there is a significant amount of mantle origin soil gas at the Taiwan 1 site. This indicates that some radon gas may have come from a deeper source, up to a few hundred meters, in the fault zones but it is likely that most of the radon of this source remain dissolved in groundwater as the temperature lowers.

The timing of the radon releasing events is assumed to occur when enough stress has accumulated to release the sorbed radon, due either to fault block motion or fluid flow associated with electrokinetic potential phenomenon, as spike-like anomalies as demonstrated in the time series (Chyi et al., 2005). The compression of fault blocks 
ought to start as soon as the stress arrives at the monitoring station. Compressive stress affects larger area vertically in the fault zone and result in the release of large amount of absorbed soil gases including radon. As the stress rises, blocks within the fault zone can have rotational or transitional motions. As the blocks are rubbing against each other, shear stress could result in a quick release of radon. Radon and other absorbed soil gases may be released quickly as the stress gradually increases in strength. Compressive stress can affect fault blocks at a great depth but shear stress can only affect fault blocks with space to move or rotate in the shallow part of the fault zone. Fluid flow is also expected to dominate in shallow depth rather than at depth. As we move closer to the hypocenter, stress may reach a maximum. Microfractures can start to develop in response to the increased compressive stress with occasional foreshocks at variable magnitudes and thus resulted in the reduction of potential energy stored in the stressed terrain. At the hypocenter, a main shock can occur at the right time with a quick release of potential energy. Finally the ensuing aftershock will release the rest of the potential energy and complete the earthquake cycle with respect to potential energy (Fig. 9). The auguring and back-filling time and the detection of radon anomalies at the university construction site discussed earlier appear to follow this potential energy grow and decay model. A natural self potential measurement at $100 \mathrm{~km}$ due west from the epicenter with electrode located in a north-south direction $60 \mathrm{~m}$ apart showed a similar change as predicted by Dolbrovolsky's model of potential energy change before the 1975 Haicheng earthquake (Zhu, 1976). The horizontal self-potential increased from $80 \mathrm{mV}$ on January 9,1975 to $170 \mathrm{mV}$ on January 28. It then decreased down to 120 $\mathrm{mV}$ on February 1 . Then it decreased quickly down to a slightly negative value on February 4. A 7.3 magnitude earthquake hit Haicheng on that day. This self-potential variation suggested that radon could be desorbed if the change exceeded the energy of absorption. The amount of this energy is being determined in our laboratory at this time. We, therefore, believe that the timing of spikelike radon anomaly is a reasonable time indicator of the incoming main shock.

\section{CONCLUSION}

Radon release from an active fault zone is sensitive to electrokinetic or self potential phenomenon related to crustal stress but significant amount of radon could come from deeper source. However, the desorption of the shallow source from superfacial soil layer created the spikelike anomalies that are more significant in forecasting earthquakes. Spike-like radon anomalies recorded in the time series at Akron 1 site demonstrated that shear stress can indeed release absorbed radon quickly as a short term phenomenon. It is likely that the spike-like anomalies observed in the time series recorded at Taiwan 1 and 3 sites representing the change of natural self-potential that triggers radon release at the monitoring sites. If stress is propagated outward from hypocenter, in a circular fashion, and the velocity of migration decreases logarithmically, then the timing of the arrival of the stress at a given site as indicated by this radon spike-like anomaly can be used to calculate the distance to the origin of the stress. By solving simultaneous equations with distances to hypocenter, time stress moving away from the hypocenter, and radon release time as unknowns, the magnitude and time of the earthquake could be estimated (Chyi et al., 2007, 2010).

The main objective of the forecast is issue warning to the general population within a few days of a major destructive earthquake, thus save precious lives. The forecast may also has the value of permitting industry to plan on their earthquake sensitive production process such as making microprocessor and grow artificial crystals. Major earthquake $>M_{L}=7.0$ occurs in Taiwan every 10 to 20 years on average since 1901 .

Acknowledgments - We appreciate the funding from the Central Geological Survey and the National Science Council grant (NSC 89-2811-m00209974) to the co-authors at National Taiwan University and the University of Akron Faculty Research grant 1541 to the first author.

\section{REFERENCES}

Chyi, L. L. (2006) Radon monitoring system for earthquake prediction. Patent Application No. 60648, 533, U.S. Patent and Trademark Office.

Chyi, L. L., Chou, C. Y., Yang, F. T. and Chen, C. H. (2001) Continuous radon measurements in faults and earthquake precursor pattern recognition. Western Pacific Earth Sciences 1(2), 227-246.

Chyi, L. L., Quick, T. J., Yang, F. T. and Chen, C. H. (2005) Soil gas radon spectra and earthquakes. Terr. Atmos. Ocean. Sci. 16, 763-774.

Chyi, L. L., Quick, T. J., Yang, F. T. and Chen, C. H. (2007) Soil radon time series and earthquake forecast. Proceedings of the International Brainstorming Session on Geochemical Precursors for Earthquakes (Sen, P. and Das, N. K., eds.), 38-41, Saha Institute of Nuclear Physics, MacMillan.

Chyi, L. L., Quick, T. J., Yang, T. F. and Chen, C.-H. (2010) The experimental investigation of soil gas radon migration mechanisms and its implication in earthquake forecast. Geofluids 10, 556-563.

Crampin, S. and Zatsepin, S. V. (1997) Modelling the compliance of crustal rock-II, Response to temporal changes before earthquake. Geophys. J. Int. 129, 495-506.

Dolbrovolsky, I. P., Zubkov, S. I. and Miachkin, V. I. (1979) 
Estimation of the size of earthquake preparation zones. Pure Appl. Geophys. 117, 1025-1044.

Eichler, B., Zimmermann, H. P. and Gaggler, H. W. (2000) Adsorption of radon on ice Surfaces. J. Phys. Chem. A104, 3126-3131.

Fu, C. C., Yang, T. F., Walia, V., Liu, T. K., Lin, S. J., Chen, C.H. and Hou, C. S. (2009) Variations of soil-gas composition around the active Chihshang Fault in a plate suture zone, eastern Taiwan. Radiat. Meas. 44, 940-944.

Hoppel, W. A., Anderson, R. V. and Willett, J. C. (1986) Atmospheric electricity in the planetary boundary layer. The Earth's Electrical Environment, 149-165, National Academy of Science.

Laskar, I., Phukon, P., Goswami, A. K., Chetry, G. and Roy, U. C. (2011) A possible link between radon anomaly and earthquake. Geochem. J. 45, this issue, 439-446.

Lide, D. R. (ed.) (2006) CRC Handbook of Chemistry and Physics. 87th ed., CRC Press, Boca Raton.

Liu, T. K., Hsieh, S., Chen, Y. S. and Chen, W. S. (2001) Thermo-kinematic evolution of the Taiwan obliquecollision mountain belt as revealved by zircon fission track dating. Earth Planet Sci. Lett. 186(1), 45-56.

Mackey, K. G., Fujita, K., Gounbina, L. V., Koz'min, B. M., Imaeva, V. S., Imaev, L. P. and Sedov, B. M. (2003) Explosion contamination of the northeast Siberian seismicity catalog: implications for natural earthquake distributions and the location of the Tanlu Fault in Russia. Bull. Seism. Soc. Am. 93(2), 737-746.

Montazeri, H., Abbasnejad, A. and Negarestani, A. (2011) Continuous radon monitoring in the Jowshan hot spring as an earthquake precursor, SE Iran. Geochem. J. 45, this issue, 463-472.

Morgan, F. D., Williams, E. R. and Madden, T. R. (1989) Streaming potential properties of westerly granite with applications. J. Geophys. Res. 94, 12449-12461.

Nazaroff, W. W. (1992) Radon transport from soil to air. Rev.
Geophys. 30(2), 137-160.

Park, S. K., Dalrymple, W. and Larson, J. C. (2007) The 2004 Parkfield earthquake: test of the electromagnetic precursor hypothesis. J. Geophys. Res., 112, B05032, 9.

Tchorz-Trzeciakiewicz, D. E. and Solecki, A. T. (2011) Seasonal variation of radon concentrations in atmospheric air in the Nowa Ruda area (Sudety Mountains) of southwest Poland. Geochem. J. 45, this issue, 455-461.

Wang, C. T., Chen, K. S., Yen, J. Y. and Chang, C. P. (2005) Deformation field over western Taiwan island using satellite InSar. Geoscience and Remote Sensing Symposium Proceedings. IEEE Int. 7, 25-29, 4570-4573.

Woith, H., Barbosa, S., Gajewski, C., Steinitz, G., Piatibratova, O., Malik, U. and Zschau, J. (2011) Periodic and transient radon variations at the Tiberias hot spring, Israel during 2000-2005. Geochem. J. 45, this issue, 473-482.

Yang, T. F., Chou, C. Y., Chen, C.-H., Chyi, L. L. and Jiang, J. H. (2003) Exhalation of radon and its carrier gases in S.W. Taiwan. Radiat. Meas. 36, 425-429.

Yang, T. F., Walia, V., Chyi, L. L., Fu, C. C., Chen, C.-H., Liu, T. K., Song, S. R., Lee, C. Y. and Lee, M. (2005) Variations of soil radon and thoron concentrations in a fault zone and prospective earthquakes in SW Taiwan. Radiat. Meas. 40, 496-502.

Yang, T. F., Wen, H. Y., Fu, C. C., Lee, H. F., Lan, T. F., Chen, A. T., Hong, W. L., Lin, S. J. and Walia, V. (2011) Soil radon flux and concentrations in hydrothermal area of the Tatun Volcano Group, Northern Taiwan. Geochem. J. 45, this issue, 483-490.

Zhu, F. M. (1976) An outline of prediction and forecast of Haicheng earthquake of $\mathrm{M}=7.3$. Proceedings of the Lectures by the Seismological Delegation of the People's Republic of China (translated by Ohnuki, M., Ong, K. M. and Chao, C.-C.), 11-19, Jet Propulsion Laboratory, California Institute of Technology for Office of Application, NASA. 